\title{
Applicability of Evoked Auditory Brainstem Responses with Complex Stimuli in Adults with Hearing Loss
}

\author{
Bruna Pias Peixe ${ }^{1}$ Débora Durigon da Silva ${ }^{1}$ Eliara Pinto Vieira Biaggio ${ }^{1}$ Rúbia Soares Bruno ${ }^{1}$ \\ Taissane Rodrigues Sanguebuche ${ }^{1}$ Michele Vargas Garcia ${ }^{1}$
}

${ }^{1}$ Department of Speech Theraqpy, Universidade Federal de Santa
Maria, Rio Grande do Sul, RS, Brazil

Int Arch Otorhinolaryngol 2018;22:239-244.

\begin{abstract}
Address for correspondence Bruna Pias Peixe, Speech Therapist, Departamento de Fonoaudiologia, Universidade Federal de Santa Maria, Av. Roraima $n^{\circ} 1000$, Santa Maria, 97105-900, Rio Grande do Sul, RS, Brazil (e-mail: brunapeixe.bp@hotmail.com).
\end{abstract}

\begin{abstract}
Keywords

- hearing

- electrophysiology

- auditory evoked response

- hearing loss

Introduction The use of the speech-evoked auditory brainstem response (ABR) shows how the brainstem operates up to the subcortex in a more complex manner than when the click-evoked ABR is used.

Objective To study the applicability of the speech-evoked ABR in adults with hearing loss. Methods The sample was composed of a study group of 11 subjects, with ages ranging between 18 and 59 years, and auditory thresholds within normal standards, with loss of up to $65 \mathrm{~dB}$ at high frequencies or up to moderately severe symmetric sensorineural hearing loss. The sample underwent a basic audiological assessment, as well as speech-evoked $A B R$ and click-evoked $A B R$, in which waves I, III and V, and V, A, C, $D, E, F$ were respectively marked. The electrophysiological assessments were performed using the SmartEP device (Intelligent Hearing Systems, Miami, FL, US).

Results For the speech-evoked $A B R$, the reference values were used in the identification and analysis of the study group. Those values found for the study group were: $V=8.56 ; A=10.97 ; C=21.33 ; D=29.51 ; E=37.93 ; F=46.96 ;$ and $O=55.97 . \ln$ the comparison between groups, the study group presented an increase in latency only in wave $C$.

Conclusion The speech-evoked $A B R$ can be performed in subjects with up to moderately severe hearing loss, and the test proved to be appropriate, because, unlike the click-evoked ABR, the former does not suffer influence of peripheral hearing loss.
\end{abstract}

\section{Introduction}

The auditory evoked response tests can be classified according to the time taken by the auditory pathway to respond to an acoustic stimulus, which may be called short, medium or long latency. The Brainstem Auditory Evoked Response (BAER) is a short-latency, objective and non-invasive test that aims to assess the electrophysiological activity of the auditory system up to the brainstem. It provides bioelectric responses resulting from successive activation of the cochlea and nerve fibers of this pathway until the portion of the lateral lemniscus. ${ }^{1}$

received

December 5, 2016

accepted

June 6, 2017

published online

September 12, 2017

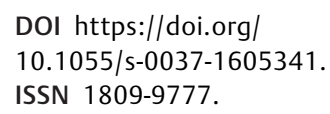

The stimulus more often used to perform this assessment is the click, because it is faster and presents a broad spectrum of frequencies, allowing the stimulus of a greater amount of fibers. ${ }^{2}$ However, other types of stimuli can be used to capture electric responses, such as the speech stimulus (consonantvowel syllable). ${ }^{3}$

This signal is a complex spectral and temporal structure that demands a synchronized neural response, thus the acoustic signals of speech can be properly perceived. The speech signal is composed of elements that are rich in harmonics and that change their frequency properties quickly. These signal
Copyright @ 2018 by Thieme Revinter
Publicações Ltda, Rio de Janeiro, Brazil

Copyright (c) 2018 by Thieme Revinter
Publicações Ltda, Rio de Janeiro, Brazil

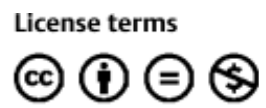


complex changes need quick and synchronous neural responses so that there is an efficient encoding of the captured sound. ${ }^{3}$ It should be emphasized that there is no need for conscious perception of sound, that is, the subject does not need to pay attention to the speech stimulus. In addition, it is considered to be a quick test that can also be used as a biomarker, ${ }^{4}$ showing the result of a speech therapy. ${ }^{5}$ This is the reason why it is important to study this stimulus in a sample who presents hearing loss, aiming to discover if it can be used in the evaluation of this population.

The BAER tests are usually performed binaurally, with the exception of the speech-evoked auditory brainstem response (ABR), which is performed only in the right ear, as suggested in the protocol of a researcher ${ }^{6}$ because of left brain dominance in language processing. Information sent by the peripheral auditory system is transmitted mostly by crossed auditory pathways, with great advantage of the contralateral hemisphere. $^{7}$

Thus, the response to this stimulus gives rise to a tracing which, before $10 \mathrm{~ms}$, includes complex $\mathrm{V}$ (positive peak) - $\mathrm{A}$ (negative peak). Later, the tracing is composed of a sequence of negative peaks (C, D, E, F and O) with latencies between 18 and $40 \mathrm{~ms}$, with $\mathrm{C}$ and $\mathrm{F}$ being the most frequent and most easily observed (Filippini, 2011). ${ }^{8}$

Brainstem responses to this stimulation can be divided into transient portion and sustained portion; respectively, the onset (beginning of the stimulus) and the frequency-following response (FFR) components of the responses. The onset responses are similar processes to the click, and they represent the response at the beginning of the stimulus and the transition from the consonant to the vowel (Russo, Nicol, Musacchia, Kraus, 2004). ${ }^{6}$ By contrast, the FFR reflects the harmonic structure of the vowel that remains during the reproduction of a periodic stimulus. It shows the overall integrity of the response in comparison with the stimulus. ${ }^{6}$ More specifically, the transition between $/ d /$ and $/ a$ / is shown in trough wave $C$, and the end of the stimulus $(/ \mathrm{a} /)$ is evidenced in trough wave $0{ }^{9}$

In the literature review, some authors (Abrams, Kraus, $2009)^{10}$ discussed the onset and FFR portions and described them in detail. This represents the importance of the tracing as a whole in the analysis, that is, both portions of the tracingresponse provide crucial and indispensable information on the form of speech encoding. The acoustic onset represents the spectral and temporal properties of the stimulus that varies according to its phonetic information. The structure of the formant is the combination between the frequency and the resonance of the vocal tract of the speaker, which are essential for the perception of vowels. The periodicity represents the sound events that occur at regular intervals and are oriented to phonetic features and speech prosody. And the frequency transition provides supra-segmental information about the intent and the emotional state of the speaker.

Although the generating sites are not defined, it is known that the speech-evoked ABR shows the operation of a larger region of the brainstem up to the subcortex, in a more complex manner than when performed with a stimulus click. ${ }^{2}$ Therefore, a delay and/or absence of waves in the speech-evoked ABR does not necessarily cause a change in the measurements as the click-evoked ABR does, because only the processes involved in the encoding of complex signals can be changed. ${ }^{11}$ A change is considered to exist in the test when there are failures in any portion of the tracing of responses. Thus, there is a deficit in synaptic triggers for the codification of the acoustic signal. As aforementioned, complex changes of the stimulus need appropriate neural responses for efficient coding. ${ }^{3}$

The hypothesis of this study is that all individuals with up to moderately severe hearing loss present the waves $\mathrm{V}, \mathrm{A}, \mathrm{C}, \mathrm{D}, \mathrm{E}, \mathrm{F}$, and $O$ in the speech-evoked $A B R$, because it is believed that this response is not influenced by peripheral hearing loss. Thus, the present study is aimed to investigate the applicability of the speech-evoked ABR in adults with hearing loss.

\section{Method}

This was a prospective, quantitative and cross-sectional study. All evaluations were performed at the outpatient audiology clinic of a university hospital. The subjects who agreed to participate in the study were informed about the procedures, risks, benefits, and confidentiality of the data of the research, and signed an informed consent form (ICF), following all the ethical principles according to Resolution 466/12 of the Brazilian Health Council. This study was approved by the Research Ethics Committee under protocol number 25933514.1.0000.5346.

To compose the study group (SG), the researchers contacted subjects that were on the waiting list of a Municipal Health Department for participation in the Hearing Health Program, users of a reference Health Center, and subjects treated by clinical audiology interns in the aforementioned hospital.

The inclusion criteria for the SG were: individuals aged between 18 and 59 years (both male and female), with auditory thresholds within normal standards, as measured by the tritonal mean $(0.5 \mathrm{kHz}, 1 \mathrm{kHz}$ and $2 \mathrm{kHz})$ with loss of up to $65 \mathrm{~dB}$ in the average of high frequencies $(2 \mathrm{kHz}, 3 \mathrm{kHz}$ and $4 \mathrm{KHz}$ ) or up to moderately severe sensorineural hearing loss, ${ }^{12}$ no chronic tinnitus, who spoke Brazilian Portuguese as mother language, were preferably right-handed, and complained of significant difficulty in speech comprehension in acoustically unfavorable environments. In addition, all individuals should have at least the $\mathrm{V}$ wave in the clickevoked ABR. The subjects were excluded when they had conductive hearing loss, asymmetric hearing between the ears, neurological disorders and chronic diseases.

The researchers assessed 330 records of patients on the waiting list of the Hearing Health Program. However, 324 of them were excluded because they did not meet all the eligibility criteria (moderately severe hearing loss: $n=28$; conductive impairment: $n=17$; hearing impairment above $65 \mathrm{~dB}$ in high frequencies: $n=12$; age under 18 or greater than 59years: $n=261$; neurological alterations: $n=6$; and chronic tinnitus coexisting with other exclusion criteria: $n=6$ ).

At the Health Center, 246 records were evaluated, but 242 subjects were excluded (hearing loss greater than moderately severe: $n=2$; conductive hearing loss: $n=4$; asymmetrical auditory thresholds: $n=23$; lack of important data: $n=9$; auditory thresholds within normal standards: 
$n=102$; and subjects below the age of 18 years or above the age of 59: $n=102$ ).

A total of 21 subjects treated by clinical audiology interns (within the target age range of the study) were contacted, but only 1 met the inclusion criteria (neurological disorders: $n=4$; chronic diseases: $n=2$; hearing loss $>65 \mathrm{~dB}$ at high frequencies: $n=3$; and chronic tinnitus alone or coexisting with other exclusion criteria: $n=18$ ). Because of the large number of exclusions, the SG was composed of 11 subjects, 7 women and 4 men.

For comparison purposes, the sample from another study ${ }^{13}$ from the same institution was used for reference values. The collections of both studies happened simultaneously. The sample was composed of 60 individuals, 30 young adults aged between 18 and 35 years, who were normal listeners without complaint of speech comprehension, and 30 young adults with normal hearing presenting complaints of speech comprehension. As there was no difference between the groups (taking into consideration the statistical analysis performed), they were grouped together, and this led to the following reference values, with their respective standard deviations (SDs): $\mathrm{V}=7.59 \mathrm{~ms}(\mathrm{SD}=2.17) ; \mathrm{A}=9.28 \mathrm{~ms}$ $(\mathrm{SD}=2.86) ; \quad \mathrm{C}=18.95 \mathrm{~ms} \quad(\mathrm{SD}=3.13) ; \quad \mathrm{D}=27.53 \mathrm{~ms}$ $(\mathrm{SD}=4.90) ; \mathrm{E}=34.76 \mathrm{~ms}(\mathrm{SD}=4.59) ; \mathrm{F}=43.92 \mathrm{~ms}(\mathrm{SD}=$ $5.13)$; and $\mathrm{O}=53.91 \mathrm{~ms}(\mathrm{SD}=4.49)$, which were used as the standard of normality for the SG of the present study.

The groups of both studies were submitted to a basic audiological assessment (anamnesis, otoscopy, tonal and vocal audiometries, impedance audiometry) and an electrophysiological assessment by means of click-evoked and speech-evoked ABRs.

The hearing tests were conducted in a soundproof booth, and the evaluations were performed using the following equipment: a Mikatos otoscope; a Phonak Fonix FA-12 audiometer; TDH39 supra-aural headphones and an Interacoustics AT 235 immittance device.

The electrophysiological procedures were performed with a SmartEP device (Intelligent Hearing Systems, Miami, FL, US). Before performing the examination, the subjects' skin was cleaned with NUPREP abrasive paste. Surface electrodes were attached with MAXXI FIX electrolytic paste and microporous bandage in the following manner: the active electrode $(\mathrm{Fz})$ at the central portion and top of the forehead; the grounding electrode (Fpz) at the central portion and bottom of the forehead; and reference electrodes (left and right mastoids) with an impedance $\leq 3 \mathrm{KOhms}$.

The click-evoked ABR was performed in a recording window of $25 \mathrm{~ms}$, with minimum stimulation of 2,048 sweeps, at a rate of 27.7/s, $100 \mathrm{~Hz}$ low-pass filter and 3,000 Hz high-pass filter, and a maximum of $10 \%$ of the number of artifacts compared with the number of sweeps in each tracing performed with rarefied polarity. The integrity of the auditory pathway was recorded at 80 decibels above normal adult hearing level (dBnHL) or $90 \mathrm{dBnHL}$ (when necessary) in both ears using insert earphones. The criteria to identify the integrity of the auditory pathway were the presence of waves I, III and V, the analysis of latency, and interpeak intervals with reproducibility of tracings.
Regarding the speech-evoked ABR, the stimulus used was the syllable /da/ with $40 \mathrm{~ms}$ at the intensity of $80 \mathrm{dBnHL}$ using insert earphones in the right ear. The following parameters were used: registration window of $60 \mathrm{~ms}$; rate of $11.10 / \mathrm{s}$; low-pass filter of $100 \mathrm{~Hz}$ and high-pass filter of $3,000 \mathrm{~Hz}$; electroencephalogram (EEG) at 30\%; alternate polarity; and an average of 3,000 sweeps from 3 scans of 1,000 sweeps with analysis on the wave resulting from the sum of these scans. Based on the same criteria of the clickevoked ABR, the tracings that were considered were only the ones in which the number of artifacts did not exceed $10 \%$ of the number of sweeps. The analysis was performed by joining latency/morphology data and, therefore, a positive peak $(V)$ was marked, followed by successive negative peaks (A, C, D, E, F and O), if they existed. It is worth mentioning that wave $\mathrm{O}$ was the last one to be marked, with no trough after it. In addition, tracings were only considered when the number of artifacts did not exceed $10 \%$ of the number of sweeps.

Three main researchers performed the markings of the tests. Later, two female speech therapists responsible for the present study reviewed the markings separately at different moments. Therefore, the markings used in the statistics of the study were agreed upon between the authors.

\section{Results}

-Fig. 1 shows the resulting waves obtained in adults presenting normal hearing and presenting hearing loss, in the SmartEP device, with markings of peak V, and troughs A, C, D, $\mathrm{E}, \mathrm{F}$, and $\mathrm{O}$.

The SG (-Table 1) was composed of 11 ears with the following audiometry settings: 3 ears with the 3-frequency pure tone average $(0.5,1 \mathrm{KHz}$ and $2 \mathrm{KHz})$ within the normal range, but with downgrade to $65 \mathrm{~dB}$ in the averages of acute frequencies ( $2 \mathrm{KHz}, 3 \mathrm{KHz}$ and $4 \mathrm{KHz}$ ); and 8 ears with sensorineural hearing loss up to the moderately severe degree in both averages. The data are shown by ear because the speech-evoked ABR was performed in the right ear.

In the analysis of the evoked responses, the SD values of each response are used to check the normality or alteration of them. In this study, when the values found in the SG (-Table 2) ${ }^{13}$ were compared with the reference values, while considering the SD of the reference values, there was an increase in latency in trough $\mathrm{C}$.

\section{Discussion}

In the present study, peak $\mathrm{V}$ and troughs $\mathrm{A}, \mathrm{C}, \mathrm{D}, \mathrm{E}, \mathrm{F}$ and $O$ were marked. However, we should note that several studies $^{2,14,19,21}$ referenced during the discussion analyzed only a few waves of the speech-evoked ABR described in the literature.

First, it should be highlighted that, when the reference values of a sample of normal listeners, ${ }^{13}$ such as the one used in the present study, are compared with those of studies conducted using other equipment, there can be a difference because the SmartEP device produces modifications in the tracings. This occurred during the comparison with a renowned study ${ }^{2}$ that 


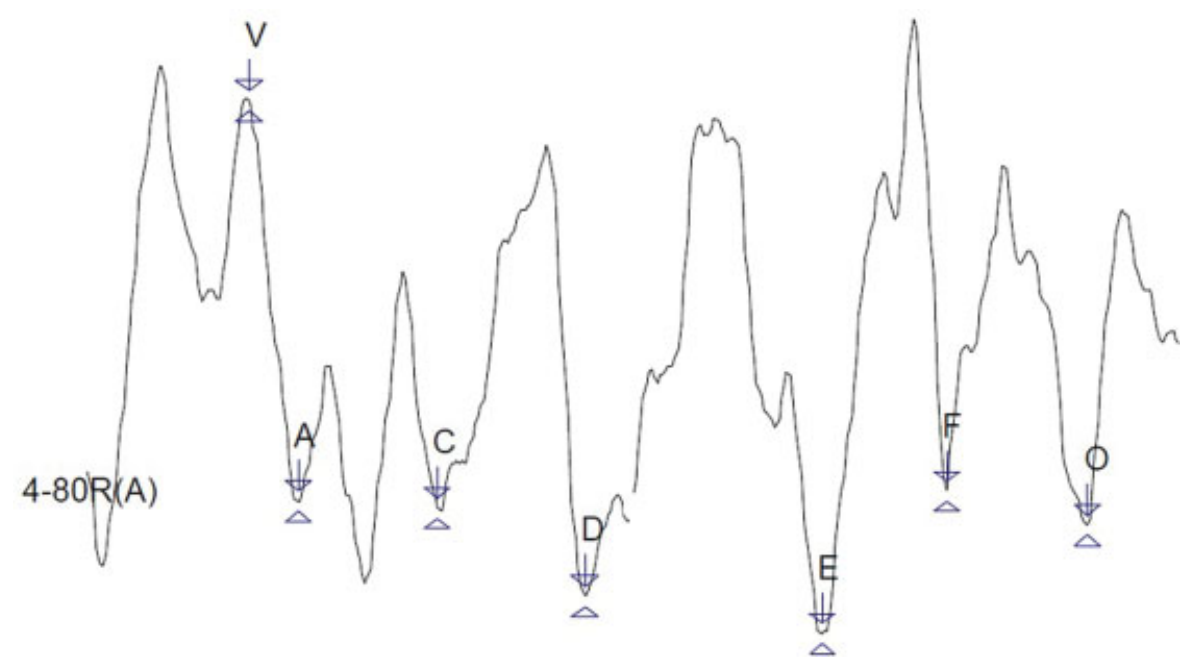

Fig. 1 Tracing of speech-evoked auditory brainstem responses of an individual with mild sensorineural hearing loss, as measured by the SmartEP device (Intelligent Hearing Systems, Miami, FL, US).

Table 1 Descriptive data for the right ear of the study group for the following variables: sex, age (years), mean of 0.5 to $2 \mathrm{kHz}$ and mean of 2 to $4 \mathrm{kHz}(\mathrm{dB} \mathrm{HL})$

\begin{tabular}{|l|l|l|l|l|l|l|l|}
\hline & $\mathbf{n}^{*}$ & Mean & SD & Min & Med & Max & $\%$ \\
\hline Females & 14 & - & - & - & - & - & 63.63 \\
\hline Males & 8 & - & - & - & - & - & 36.36 \\
\hline Age (years) & - & 51.73 & 10.31 & 23 & 56 & 59 & - \\
\hline Mean of 0.5 to 2 kHz - RE & 11 & 29.8 & 11.12 & 16.6 & 31.6 & 56.66 & - \\
\hline Mean of 0.5 to 2 kHz - LE & 11 & 29.63 & 8.74 & 15 & 28.33 & 51.66 & - \\
\hline Mean of 2 to 4kHz RE & 11 & 40.3 & 11.57 & 25 & 38.33 & 65 & - \\
\hline Mean of 2 to 4kHz - LE & 11 & 39.16 & 11.37 & 31.66 & 33.33 & 50 & - \\
\hline
\end{tabular}

Abbreviations: *, data for the right ear; \%, percentage; dB HL, decibels hearing level; LE, left ear; Max, maximum; Med, median; Min, minimum; n, total number of ears; RE, right ear; SD, standard deviation.

Note: Hypothesis testing for the average.

used the Audera (Grason-Stadler [GSI], Eden Prairie, MN, US) device to apply the speech-evoked ABR to normal individuals with ages between 19 and 32 years: they found lower values than the ones in the present research. Moreover, another study ${ }^{14}$ which was performed using the Navigator Pro device with a sample of 19 young adults, normal listeners, aged between 20 and 26 years old, found lower latencies of the troughs $\mathrm{F}$ and $\mathrm{O}$.

The same study ${ }^{14}$ was also composed of another group of 18 elderly patients with hearing loss at high frequencies,

Table 2 Comparison of the mean latencies (ms) of the speech-evoked auditory brainstem responses of the study group with the standard deviations of the reference values used in the study by Silva $(2016)^{13}$

\begin{tabular}{|l|l|l|l|l|l|l|l|l|}
\hline & N & Mean & SD & Min & Max & Mean $^{*}$ & SD $^{*}$ & $p$ \\
\hline Peak V & 10 & 8.56 & 2.18 & 5.88 & 12.1 & 7.59 & 2.17 & 0.192 \\
\hline Trough A & 10 & 10.97 & 3.31 & 7.63 & 17.4 & 9.28 & 2.86 & 0.095 \\
\hline Trough C & 10 & 21.33 & 3.01 & 15.88 & 26.1 & 18.85 & 3.13 & $\mathbf{0 . 0 3 3}$ \\
\hline Trough D & 10 & 29.51 & 4.6 & 20.25 & 34.2 & 27.53 & 4.9 & 0.234 \\
\hline Trough E & 10 & 37.93 & 3.96 & 31.38 & 41.63 & 34.76 & 4.59 & 0.057 \\
\hline Trough F & 10 & 46.96 & 4.36 & 40.5 & 53.8 & 43.92 & 5.13 & 0.093 \\
\hline Trough O & 11 & 55.97 & 7.79 & 48.75 & 58.8 & 53.91 & 4.59 & 0.168 \\
\hline
\end{tabular}

Abbreviations: Max, maximum; Mean*, mean of the reference values; Min, minimum; N, number of right ears of the sample; SD, standard deviation; $\mathrm{SD}^{*}$, standard deviation of the reference values.

Note: Hypothesis testing for the average. 
aged between 61 and 78 years, as well as some subjects of the sample of the present study (-Table $\mathbf{1}$ ). The study aimed to check the effects that can be caused by presbycusis in speechevoked responses. The evaluation was performed in both ears, but they used the average between them, and the values found in this group were: peak $V=6.7$; trough $A=7.75$; trough $\mathrm{D}=23.0$; trough $\mathrm{E}=31.39$; trough $\mathrm{F}=39.70$; and trough $\mathrm{O}=48.70$. Therefore, the findings of the present study corroborate those of the study cited ${ }^{14}$ only for peak V and troughs A and O, using the SDs found in the SG to compare the results (-Table 2 ). The values that are not in agreement are slightly lower in the aforementioned study. However, it should be highlighted that the subjects in both studies have a different age range, which limits a conclusion of this comparison of latencies. As previously noted, ${ }^{15}$ aging causes distortions in retrocochlear cells, changing the timing of the central auditory pathway, in addition to causing structural changes in the auditory nerve, along the central pathways in the brainstem, and in the temporal lobe.

It is believed that comparing both groups in the same age range may be an interesting procedure to observe hearing loss behavior for the speech-evoked ABR. The latency values found in the study ${ }^{14}$ for the group of young normal listeners were: peak $\mathrm{V}=6.68$; trough $\mathrm{A}=7.72$; trough $\mathrm{D}=23.09$; trough $\mathrm{E}=31.19$; trough $\mathrm{F}=39.50$; and trough $\mathrm{O}=48.25$. Taking into account the values and SDs of the SG (- Table 2 ), the values of the complex $\mathrm{V}-\mathrm{A}$ and trough $\mathrm{O}$ corroborate those of the present study. This shows that individuals with hearing loss can have the same perception of the beginning and the end of the syllable /da/, as the normal listeners in the study by Werff and Burns. ${ }^{14}$ Again, the values that do not agree with the present research are slightly lower.

In the literature, there are no other studies on hearing loss in the research of the speech-evoked ABR, as also evidenced in a review that sought to examine the applicability of the speech-evoked ABR in the clinical practice. ${ }^{16}$ It confirmed the lack of research on the population that is represented in the present study. In addition, this study underscores the importance of the response of the auditory pathway at the level of the brainstem and at higher levels, for differential diagnosis. It is known that click-evoked ABR is used mainly in the differential diagnosis of cochlear and retrocochlear disorders. ${ }^{17}$ There is a limitation, however, because only sensorineural losses up to the moderate degree have waves with absolute latencies and normal interpeaks. ${ }^{18}$

In comparison, the speech-evoked ABR offers the possibility of research on the auditory pathway at higher levels than the click-evoked ABR, because, as mentioned before, it is known that it allows the view of an upper region of the brainstem up to the subcortex. ${ }^{2}$ As can be seen in the SG, the responses could be recorded for the consonant $/ \mathrm{d} /$ and the vowel $/ \mathrm{a} /$ of the stimulus, that is, both portions of the tracing, the transient portion (V-A complex) and the sustained portion (FFR), even in individuals with a moderately severe degree of hearing loss.

Considering the sample of the SG (-Table 1), all individuals reported difficulty in speech comprehension or another factor that would indicate a disorder of any central auditory skills. The authors of this study assumed that the individuals who presented an absence of a wave (-Table 2) may have hearing disorders, because it is known that the speech-evoked ABR is a valid tool to evaluate the auditory function of the brainstem in subjects who have auditory processing disorders. ${ }^{19}$

The final analysis of the data from the present study (-Table 2) shows that the mean latency values of the SG are equivalent to the reference values, with the exception of wave $\mathrm{C}$, which shows an increase in latency, when the SD is taken into consideration. A change in this wave, in particular, reflects a failure in neural encoding at the time of transition from the consonant to the beginning of vocalization. ${ }^{9}$ This change in sound information must be perceived by the auditory pathway, otherwise there may be difficulty in speech comprehension. To avoid this failure and allow speech perception to happen fully, there have to be quick and synchronous neural responses that can encode sound efficiently, thus capturing the harmonic changes and frequencies that occur quickly and suddenly during speech. For such purpose, these skills can be observed through the analysis of wave $C$ on the FFR.

Given the small amount of studies with adults with hearing loss, ${ }^{16}$ the present study discusses the data found with younger age groups. Such a comparison with children does not become a problem, because unlike cortical responses, the neuromaturation of the auditory pathway for the encoding of speech in the brainstem is completed at around 5 years of age. ${ }^{20}$

A study ${ }^{19}$ was conducted to compare the development of brainstem response in 40 subjects with ages between 7 and 24 years, 20 normal listeners and 20 individuals with auditory processing disorder (APD), using the Biologic device. The latency values in the normal group were: peak $\mathrm{V}=6.54$; trough $A=8.0$; trough $C=18.12$; and trough $F=40.27$. In the group with APD, the values were: peak $V=7.55$; trough $\mathrm{A}=9.10$; trough $\mathrm{C}=19.45$; and trough $\mathrm{F}=40.93$. These data indicate an increase in the latencies of peak $V$ and trough $A$ in the group with APD, and show that these individuals also have more difficulty in detecting the transient portion of the stimulus $(/ \mathrm{d} /)$. Although the latency values of both groups in the present study were increased, they are similar to the findings described before, with the exception of wave F, which was substantially increased in the SG.

The latency values for the normal group found in the aforementioned study served as a standard for another study, ${ }^{21}$ which aimed to compare 36 children aged between 7 and 11 years, 18 with typical language development and 18 with a phonological disorder. The latency values for the normal group were: peak $V=7.41$; trough $A=9.39$; trough $C=19.42$; and trough $\mathrm{F}-=40.10$. For the group with phonological disorders, the values were: peak $\mathrm{V}=8.58$; trough $\mathrm{A}=10.32$; trough $\mathrm{C}=18.76$; and trough $\mathrm{F}=40.00$. Again, the waves $\mathrm{V}$ and $\mathrm{A}$ presented increased latency in the group diagnosed with phonological disorders, and the values of the present study corroborate these findings, with the exception of wave $F$ of the SG. Both mentioned studies ${ }^{9,10}$ provide the same information. It is believed that the change in wave $F$, which is part of the sustained portion (FFR), could lead to difficulty in encoding the harmonics present in speech sounds, which is transmitted by the frequency of the stimulus. However, for some reason, the 
brainstem does not record this information, and thus speech comprehension is compromised.

A study ${ }^{22}$ compared the performance in different tests of 20 children aged between 7 and 11 years, 10 with typical language development and 10 with a diagnosis of stuttering. In the speech-evoked ABR, which was performed using the SmartEP device, the normal group presented the following latency values: peak $\mathrm{V}=6.93$; trough $\mathrm{A}=8.58$; trough $\mathrm{C}=$ 17.14; and trough $F=40.78$. The values for the group with stuttering were: peak $\mathrm{V}=6.54$; trough $\mathrm{A}=8.33$; trough $\mathrm{C}=20.32$; and trough $\mathrm{F}=40.10$. Just as in the present study, only wave $C$ showed increased latency between the groups, which indicates greater difficulty in understanding the beginning of the sustained portion $(/ \mathrm{a} /)$. Another study, ${ }^{23}$ which involved sensorineural but unilateral and mild hearing loss, showed increased latency in trough $\mathrm{D}$ and, again, in trough $\mathrm{C}$ as well, indicating the same difficulty in capturing that part of the stimulus.

A recent study, ${ }^{24}$ which sought to demonstrate the applicability of the speech-evoked ABR in the clinical practice, found a strong relationship between changes in auditory processing and changes in the speech-evoked ABR. In the study, an analysis of 27 medical records of subjects aged between 7 and 15 years, with changes in the speech-evoked ABR, was performed. A total of 23 subjects presented changes in auditory processing. Thus, this research indicated that the speech-evoked ABR may assist in the assessment of auditory processing, reinforcing the assumption of the present study, that is, the absence of waves can be due to changes in the auditory processing of the sample.

The speech-evoked ABR is not influenced by up to moderately severe hearing loss; moreover, it can provide information about auditory processing disorders, serving as a complementary evaluation of the hearing processing ${ }^{1,9,24}$ Additionally, it does not depend on the conscious participation of the patient in the assessment, thus it is a quick and objective test. It may also be used as a biomarker, as suggested in a previous study for both speech therapy and learning disorders, as well as for auditory training. ${ }^{4,5,25}$ Therefore, further research is suggested with individuals with hearing loss, using other equipment, as well as the SmartEP device, for future comparisons.

\section{Conclusion}

The speech-evoked ABR could be performed in subjects with up to moderately severe hearing loss. The test proved to be appropriate, because, unlike the click-evoked ABR, it was not influenced by peripheral hearing loss.

\section{References}

1 Fernandes LCBC, Gil D, Maria SLS, Azevedo MF. Potencial evocado auditivo de tronco encefálico por via óssea em indivíduos com perda auditiva sensorioneural. Rev CEFAC 2013;15(03): 538-545

2 Rocha CN, Filippini R, Moreira RR, Neves IF, Schochat E. Potencial evocado auditivo de tronco encefálico com estímulo de fala. PróFono R Atual Cient 2010;22(04):479-484
3 Kraus N, Nicol T. Aggregate neural responses to speech sounds in the central auditory system. Speech Commun 2003;41(01):35-47

4 Sanfins MD, Borges LR, Ubiali T, Colella-Santos MF. Speech auditory brainstem response (speech $A B R$ ) in the differential diagnosis of scholastic difficulties. Rev Bras Otorrinolaringol (Engl Ed) 2017;83(01):112-116

5 Banai K, Abrams D, Kraus N. Sensory-based learning disability: Insights from brainstem processing of speech sounds. Int J Audiol 2007;46(09):524-532

6 Russo N, Nicol T, Musacchia G, Kraus N. Brainstem responses to speech syllables. Clin Neurophysiol 2004;115(09):2021-2030

7 Kimura D. From ear to brain. Brain Cogn 2011;76(02):214-217

8 Filippini R. Eficácia do treinamento auditivo por meio do potencial evocado para sons complexos nos transtornos de audição e linguagem [dissertation]. São Paulo: Universidade de São Paulo; 2011

9 Skoe E, Kraus N. Auditory brain stem response to complex sounds: a tutorial. Ear Hear 2010;31(03):302-324

10 Abrams D, Kraus N. Auditory pathway representation of speech sound in humans. In: Katz J, Hood L, Burkard R, Medwetsky L. Handbook of clinical audiology. Baltimore: Lippincott. Williams \& Wilkins; 2009:611-626

11 Song JH, Banai K, Russo NM, Kraus N. On the relationship between speech- and nonspeech-evoked auditory brainstem responses. Audiol Neurootol 2006;11(04):233-241

12 Lloyd LL, Kaplan H. Audiometric interpretation: a manual of basic audiometry. Baltimore: University Park Press; 1978:12-17

13 Silva DD. Funcionalidade da via auditiva em nível de tronco encefálico em indivíduos jovens com e sem queixa de compreensão de fala [dissertation]. Santa Maria, Brazil: Universidade Federal de Santa Maria; 2016

14 Vander Werff KR, Burns KS. Brain stem responses to speech in younger and older adults. Ear Hear 2011;32(02):168-180

15 Bess FH, Hedley-Williams A, Lichtenstein MJ. Avaliação audiológica dos idosos. In: Musiek FE, Rintelmann WF. Perspectivas atuais em avaliação auditiva. Barueri: Manole; 2001:343-370

16 Sanfins MD, Colella-Santos MF. A review of the clinical applicability of speech-evoked auditory brainstem responses. J Hear Sci 2016;6(01):9-16

17 Pinto FR, Matas CG. Comparação entre limiares de audibilidade e eletrofisiológico por estímulo tone burst. Rev Bras Otorrinolaringol 2007;73(04):513-522

18 Momensohn-Santos TMM, Russo ICP. Prática da audiologia clínica. 6 ed. São Paulo: Cortez; 2007

19 Filippini R, Schochat E. Potenciais evocados auditivos de tronco encefálico com estímulo de fala no transtorno do processamento auditivo. Rev Bras Otorrinolaringol (Engl Ed) 2009;75(03):449-455

20 Johnson KL, Nicol T, Zecker SG, Kraus N. Developmental plasticity in the human auditory brainstem. J Neurosci 2008;28(15): 4000-4007

21 Gonçalves IC. Potencial evocado auditivo de tronco encefálico com estímulo de fala em crianças com distúrbio fonológico [dissertation]. São Paulo: Universidade de São Paulo; 2009

22 Gonçalves IC. Aspectos audiológicos da gagueira: evidências comportamentais e eletrofisiológicas [thesis]. São Paulo: Universidade de São Paulo; 2013

23 Ubiali T, Sanfins MD, Borges LR, et al. Relato de caso: Potenciais Evocados Auditivos de Tronco Encefálico (PEATE) com estímulos de fala e clique em um caso de perda auditiva neurossensorial de grau leve unilateral [internet] 2015 Avaliable at: http://www.audiologiabrasil.org.br/eiabauru2015/anais2015/resumos/R0271-3.html Accessed: october 10, 2016

24 Rocha-Muniz CN, Filippini R, Neves-Lobo IF, et al. Can speechevoked Auditory Brainstem Response become a useful tool in clinical practice? CoDAS 2016;28(01):77-80

25 Johnson KL, Nicol TG, Kraus N. Brain stem response to speech: a biological marker of auditory processing. Ear Hear 2005;26(05): 424-434 